\title{
Intrinsic variability of the Antarctic Circumpolar Current system: low- and high-frequency fluctuations of the Argentine Basin flow
}

\author{
G. Sgubin ${ }^{1}$, S. Pierini ${ }^{2}$, and H. A. Dijkstra ${ }^{3}$ \\ ${ }^{1}$ Institut Pierre Simon Laplace (IPSL), Paris, France \\ ${ }^{2}$ Dipartimento di Scienze e Tecnologie, Università di Napoli Parthenope, Centro Direzionale, Isola C4, 80143 Naples, Italy \\ ${ }^{3}$ Institute for Marine and Atmospheric research Utrecht, Utrecht University, Utrecht, the Netherlands
}

Correspondence to: S. Pierini (stefano.pierini@uniparthenope.it)

Received: 15 September 2013 - Published in Ocean Sci. Discuss.: 5 November 2013

Revised: 21 January 2014 - Accepted: 27 February 2014 - Published: 10 April 2014

\begin{abstract}
In this paper, the variability of the Antarctic Circumpolar Current system produced by purely intrinsic nonlinear oceanic mechanisms is studied through a sigmacoordinate ocean model, implemented in a large portion of the Southern Ocean at an eddy-permitting resolution under steady surface heat and momentum fluxes. The mean transport through the Drake Passage and the structure of the main Antarctic Circumpolar Current fronts are well reproduced by the model. Intrinsic variability is found to be particularly intense in the Subantarctic Front and in the Argentine Basin, on which further analysis is focused. The lowfrequency variability at interannual timescales is related to bimodal behavior of the Zapiola Anticyclone, with transitions between a strong and collapsed anticyclonic circulation in substantial agreement with altimeter observations. Variability on smaller timescales shows clear evidence of topographic Rossby-wave propagation along the eastern and southern flanks of the Zapiola Rise and of mesoscale eddies, also in agreement with altimeter observations. The analysis of the relationship between the low- and high-frequency variability suggests possible mechanisms of mutual interaction.
\end{abstract}

\section{Introduction}

Ocean model studies of various degrees of complexity forced by steady forcing have suggested in the last two decades that a substantial fraction of the low-frequency variability (LFV) of oceanic frontal structures (ranging from the interannual to the decadal and interdecadal timescales) may be due to highly nonlinear oceanic mechanisms internal to the ocean system: this is the so-called "intrinsic" LFV variability, that can advantageously be analyzed in the conceptual framework of dynamical systems theory (e.g., see Dijkstra, 2005; Dijkstra and Ghil, 2005, for reviews). The mechanisms can involve barotropic and baroclinic instability, eddymean flow interaction, Rossby wave propagation and interaction with topographic and coastal features. In general, identifying the intrinsic part of the ocean variability, and the modality through which it emerges, is necessary to assess the role played by the ocean in the global climate. In addition, studying these ocean changes is fundamental also from a modeling point of view, as they may not be properly represented even in high-resolution general circulation models due to their high sensitivity to the parameterization of unresolved processes. Most studies have been devoted to the major mid-latitude western boundary currents and their extensions, such as the Kuroshio (e.g., Qiu and Miao, 2000; Schmeits and Dijkstra, 2001; Pierini, 2006, 2008; Pierini and Dijkstra, 2009; Pierini et al., 2009), the Gulf Stream (e.g., Schmeits and Dijkstra, 2001; Quattrocchi et al., 2012), and the Agulhas Current (e.g., Dijkstra and De Ruijter, 2001; Le Bars et al., 2012).

A good candidate for considerable intrinsic LFV is also the Antarctic Circumpolar Current (ACC) system (e.g., Rintoul et al., 2001) and its complex frontal structure in the Southern Ocean. The ACC plays an important role in the global climate through local water mass formation, ocean carbon sequestration and heat storage, and because of its ability to connect climate signals at all longitudes. Hogg and Blundell (2006) analyzed the LFV of the ACC by using an idealized multilayer quasi-geostrophic model forced by 
steady winds. Their simulations display robust intrinsic LFV, which is shown to involve a positive feedback between baroclinic eddies and the mean circulation. Penduff et al. (2011) analyzed the sea level expression of intrinsic LFV in simulations of an eddy-permitting ocean general circulation model (OGCM), and found their results in the Southern Ocean to be basically consistent with those of Hogg and Blundell (2006). O'Kane et al. (2013) used an OGCM (including sea ice) to identify a Southern Ocean southeast Pacific mode of intrinsic LFV through a suite of experiments that include low-frequency (ENSO, SAM) and high-frequency stochastic forcing. Giarolla and Matano (2013) used long time series of sea surface height ( $\mathrm{SSH})$, sea surface temperature and wind stress curl to determine the main modes of LFV of the Southern Ocean circulation, but they did not investigate its intrinsic component.

An oceanic region particularly relevant for climate that affects the Southern Ocean dynamics, and where important LFV was documented, is the Argentine Basin (AB), located in the South Atlantic sector near the South American coast. The $A B$ is a crucial region where strongly contrasted water masses meet and mix (Fig. 1), and where the circulation is likely to influence meridional water exchanges between the Southern Ocean and subtropical latitudes (Piola and Gordon, 1989) with associated strong impacts on the global climate system. An intense barotropic anticylonic circulation called Zapiola Anticyclone (ZA) was documented over the Zapiola Rise (ZR), a high sedimentary deposit located in the middle of the AB (Weatherly, 1993; Whitworth et al., 1991; Saunders and King, 1995). The ZA affects considerably the surface exchanges between the ACC and the South Atlantic Current (Smythe-Wright and Boswell, 1998) and is supposed to contribute to determine global deep water mass characteristics (Garzoli et al., 2008).

The ACC dominates the southern part of the basin, splitting into two major fronts, the Polar Front and the Subantarctic Front (Fig. 1). The latter flows northwards after leaving the Drake Passage, forming the Malvinas Current, which transports cold and relatively fresh subantarctic waters equatorward. Its return flow eventually aligns with the southern edge of the ZR and represents the local manifestation of the Subantarctic Front. This front and the Polar Front join at around $\left(49^{\circ} \mathrm{S}, 45^{\circ} \mathrm{W}\right)$ and diverge further east. From the north, the warm and salty Brazil Current flows southward along the continental shelf, colliding with the Malvinas Current at around $38^{\circ} \mathrm{S}$, where the very energetic and turbulent region known as the Malvinas-Brazil Current Confluence is created.

Significant LFV of the ZA was observed with in situ (Hughes et al., 2007) and altimeter data (Saraceno et al., 2009). Saraceno et al. (2009) documented for the first time that the ZA flow may significantly decrease in strength or even vanish over an interannual timescale, with a cyclonic pattern emerging from time to time. Bigorre and Dewar (2009) developed an idealized

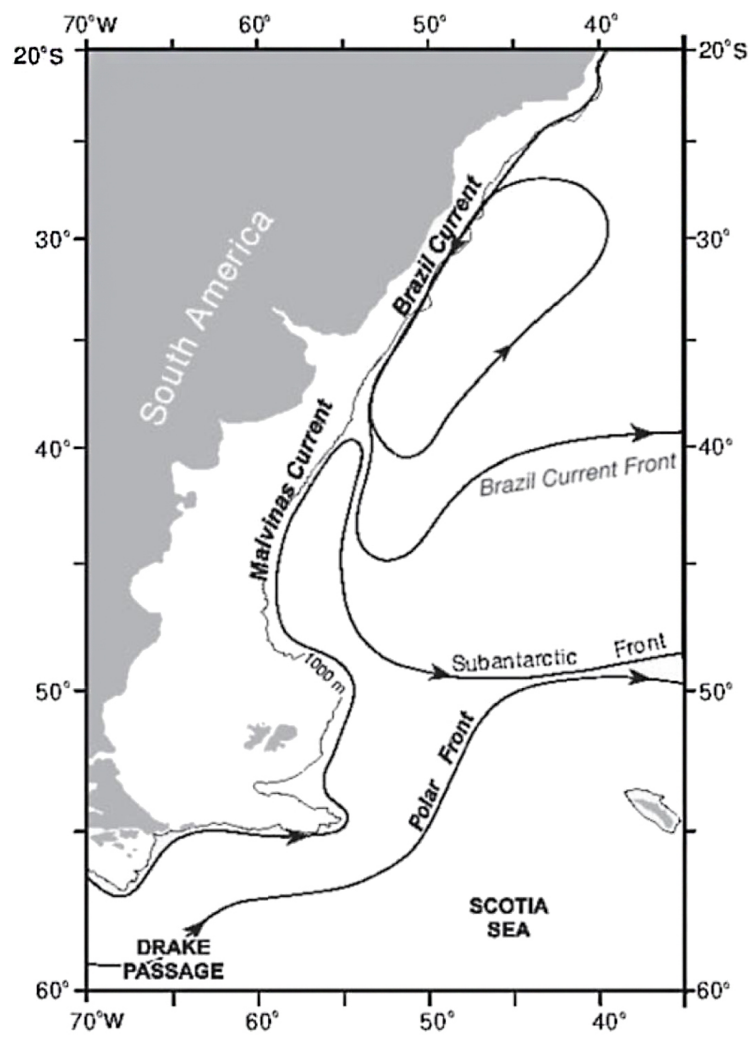

Fig. 1. Sketch of the upper-layer circulation in the southwestern Atlantic (from Saraceno et al., 2004).

quasi-geostrophic ocean process study about the circulation around a large-scale topographic anomaly: the role of bottom friction and eddy diffusivity was found to be consistent with the theory proposed by Dewar (1998) for the mean flow, moreover the modeled LFV was shown to bear important similarities to that observed. Venaille et al. (2011) found intrinsic high- and low-frequency variability of the ZA in their comprehensive ocean model, and explained the internal part as the result of an eddy-driven stochastic process. In the same basin also high-frequency fluctuations were observed (Fu et al., 2001; Tai and $\mathrm{Fu}, 2005$ ), and were interpreted in terms of topographic Rossby modes (Weijer et al., 2007a, b) and mesoscale variability (Fu, 2007).

In this paper, a model study aimed at identifying and analyzing the intrinsic variability of the ACC system, with a focus on its Subantarctic Front and relative effect on the $\mathrm{AB}$ flow, is presented. A primitive equation sigma-coordinate ocean model is implemented in a large portion of the Southern Ocean with an eddy-permitting resolution under steady forcing; the climatological forcing and the stratification are substantially idealized, while the topography (that plays a fundamental role at these high latitudes) is represented in more detail (Sect. 2). In Sect. 3 the LFV of the model flows is analyzed, with an emphasis on the $\mathrm{AB}$ where the highest level of variance is found. Regime switches occurring 


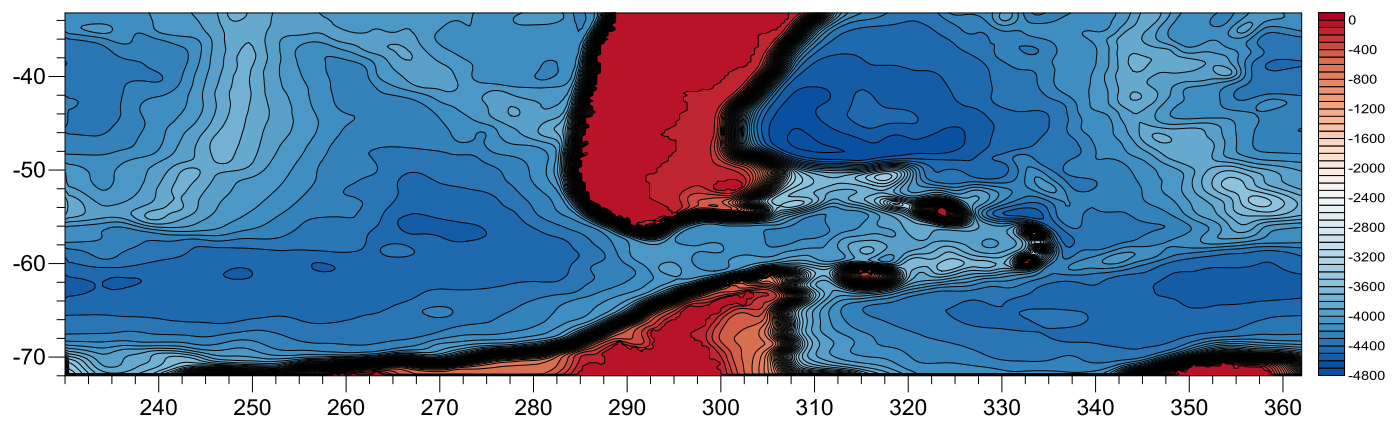

Fig. 2. Domain of integration and bottom topography (in m).

on interannual timescales of the $\mathrm{AB}$ flow are found to share important similarities with the long-term variations of the ZA as observed by Saraceno et al. (2009). In Sect. 4 the intrinsic high-frequency variability (HFV) in the $\mathrm{AB}$, emerging as a residual from the LFV, is analyzed through a wavelet analysis and interpreted in terms of topographic Rossby waves and mesoscale eddies. In Sect. 5 the relation between the LFV and the HFV is analyzed by introducing dynamical indices, and possible mechanisms of mutual interaction are suggested. Finally, in Sect. 6 conclusions are drawn.

\section{The model}

The model used in this work (Sgubin, 2012) is the Princeton Ocean Model (POM) developed by Blumberg and Mellor in 1977 and subsequently improved and updated (for general information see www.aos.princeton.edu/ WWWPUBLIC/htdocs.pom/). POM is a primitive equation sigma-coordinate model that contains a turbulence submodel for vertical mixing based on the Mellor-Yamada scheme (Mellor and Yamada, 1982). Details of the model equations and numerical solution techniques can be found in the POM user's guide (Mellor, 2003). The quantitative success of the ZA circulation model of de Miranda et al. (1999) was attributed to the use of this kind of vertical discretization (see also Barnier et al., 2006, for relevant modeling issues).

The model domain includes Pacific and Atlantic sectors of the Southern Ocean, extending meridionally from 33.2 to $72^{\circ} \mathrm{S}$ and longitudinally from 120 to $0^{\circ} \mathrm{W}$ (Fig. 2). Periodic boundary conditions along the eastern and western meridional boundaries are imposed with a $12^{\circ}$ transition region (with $10^{\circ}$ to the west and $2^{\circ}$ to the east; in that region the bathymetry is interpolated so as to match at the two boundaries). On the northern and southern boundaries free-slip boundary conditions are imposed at all depths.

The Mercator grid is adopted with the ETOPO5 bathymetry data (available online at http://www.ngdc.noaa. gov/) on a grid with a horizontal spatial resolution of one-fifth of a degree in latitude $(\sim 22 \mathrm{~km})$ and two-fifths of a degree in longitude $(\sim 13.75-37.2 \mathrm{~km})$. A limitation of sigma-coordinate models is related to the existence of pressure gradient errors that arise when computing the horizontal pressure gradient near a steep topography (e.g., Haney, 1991; Beckmann and Haidvogel, 1993). This error is caused by large numerical truncations in the transformation from the $z$ coordinate to the sigma coordinate. A reduction of such errors to acceptable values can be achieved by properly smoothing the bathymetry according to a criterion involving the bottom slope and the horizontal and vertical grid resolution. At the same time, such smoothing should retain the main features of the topography in order to consistently reproduce the interactions between the flow and the oceanic bottom, and should avoid hydrostatic inconsistency. This problem was successfully handled by Barnier et al. (1998), Marchesiello et al. (1998) and de Miranda et al. (1999) in setting up a consistent model for the South Atlantic circulation. We have therefore applied the method of Barnier et al. (1998) to obtain a model topography that reduces drastically the pressure gradient error. The method imposes an upper bound on the maximum relative variation $r_{h}$ of the model's ocean depth, defined as

$$
\begin{aligned}
& r_{h}(i, j)= \\
& \quad \frac{2 \max [|h(i+1, j)-h(i, j)|,|h(i, j+1)-h(i, j)|]}{\min [|h(i+1, j)+h(i, j)|,|h(i, j+1)+h(i, j)|]},
\end{aligned}
$$

where $h$ is the local water depth. By imposing $r_{h}<0.3$ the error has been reduced by two orders of magnitude compared to the unsmoothed topography case. Furthermore, in order to avoid hydrostatic inconsistency related to the vertical integration scheme, the maximum relative increase in bottom topography must be less than the distance between two consecutive sigma levels (Barnier et al., 1998). We have thus performed a further smoothing to satisfy this requirement for every vertical level.

The Smagorinsky parameterization has been used for the horizontal eddy viscosity with the dimensionless HORCON parameter (Mellor, 2003) $H=0.12$. The model has 12 vertical sigma levels and is integrated for 80 years from motionless initial conditions with external and internal time steps $\Delta t_{\mathrm{e}}=20 \mathrm{~s}$ and $\Delta t_{\mathrm{i}}=600 \mathrm{~s}$, respectively. Following the 

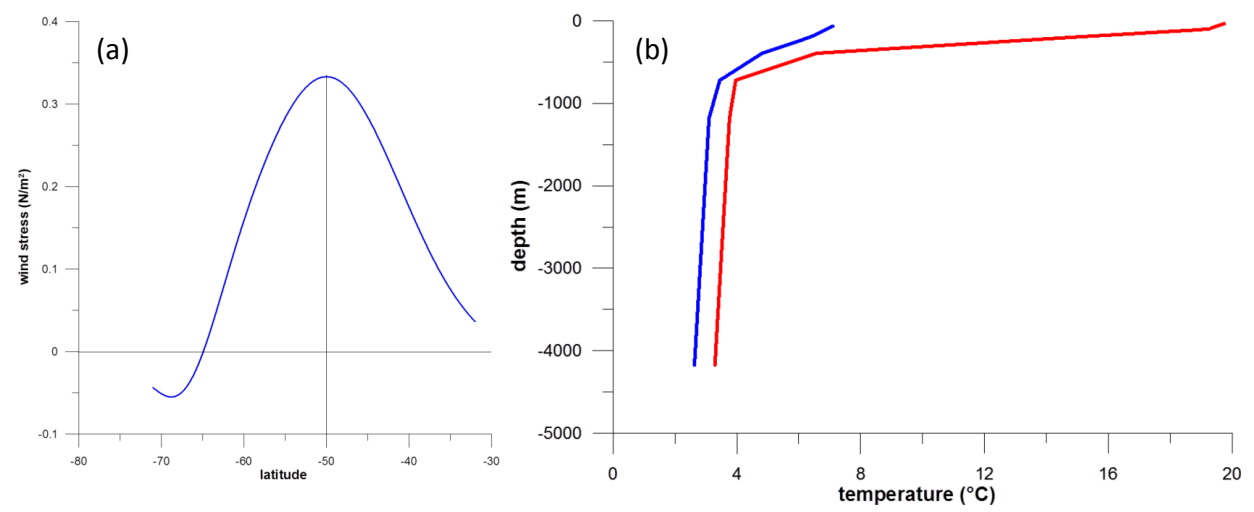

Fig. 3. (a) Steady zonal wind stress profile used to force the circulation model. (b) Initial stratifications (red/blue line: temperature profile at the northernmost/southernmost latitude).

approach typical of process studies of the intrinsic LFV, an idealized but relatively realistic steady zonal wind stress field is used: Fig. 3a shows the wind stress profile based on the Trenberth et al. (1989) climatology. The initial stratification, again idealized but relatively realistic, is shown in Fig. 3b for the temperature (the salinity has been held constant): it takes into account the vertical as well as the meridional density gradient, which effectively influences the zonal flow at Drake Passage. In order to sustain such a stratification, idealized steady surface heat fluxes have been imposed: their spatial structure (varying sinusoidally in latitude) has been empirically evaluated so that the initial stratification is not significantly altered during the simulations.

Figure 4 shows the volume transport through the Drake Passage: the average value of $\sim 116 \mathrm{~Sv}$ is in reasonable agreement with the real estimated value of $\sim 130 \mathrm{~Sv}$ (e.g., Rintoul et al., 2001); an energetic HFV is present in the signal while the LFV in this integrated parameter appears weaker. Figure 5a and b show the temporal means of the SSH $\eta$ and of the depth-integrated current $\boldsymbol{u}$, respectively. Figure $5 \mathrm{c}$ is a zoom of Fig. 5b limited to the southwestern Atlantic (one arrow out of six is drawn). The position and structure of the local ACC branches, i.e., those associated with the Polar Front and the Malvinas Current are captured quite well by the model (e.g., Rintoul et al., 2001; Saraceno et al., 2004, compare with Fig. 1 from that paper). The ZA has the correct shape and location, being centered at $\sim 315^{\circ} \mathrm{E}, 45^{\circ} \mathrm{S}$. The Polar and Subantarctic fronts meet correctly at around $50^{\circ} \mathrm{S}$ just east of $45^{\circ} \mathrm{W}$, and diverge further east (see Fig. 5b), as in the real ocean.

The Brazil Current and the Subtropical Front (located at around $39^{\circ} \mathrm{S}$ ) associated with the Malvinas-Brazil Current Confluence are absent due to the choice of the northern latitude of the domain of integration and of the wind forcing. Thus, the flow along the South American coast is unrealistic north of around $40^{\circ} \mathrm{S}$. However, this limitation does not affect our analysis, which is mainly focused on the intrinsic variability of the ZA directly induced by changes of the ACC

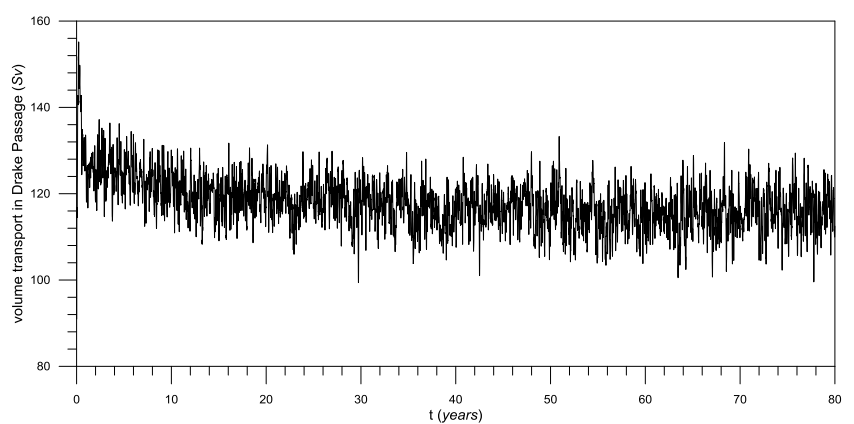

Fig. 4. Volume transport across the Drake Passage.

frontal system, particularly through its Subantarctic Front (this is in fact an innovative aspect of the present study, in which these sources of intrinsic variability can be isolated). Thus, the branch of the Subantarctic Front indicated by the red arrow in Fig. $5 \mathrm{c}$ does not derive from the Malvinas return flow (which is absent for the same reason discussed above), but from a southward current which, mainly because of topographic interactions, acquires nonetheless the correct shape and location.

\section{Intrinsic low-frequency variability}

In this section the LFV produced by the model is presented and discussed. The low-frequency signal has been derived by applying a moving average with $T=200$ days at each grid point. The decimal logarithm of the resulting rms (root mean square) of the SSH is shown in Fig. 6. Apart from a moderate variability in regions of strong topographic variations between $\sim 230-260^{\circ} \mathrm{E}$ and $345-360^{\circ} \mathrm{E}$, a very intense LFV is present all along the Subantarctic Front between $\sim 302$ and $345^{\circ} \mathrm{E}$. The particularly intense variability across the southern topographic limits of the $\mathrm{AB}$ is consistent with the findings of Saraceno et al. (2009). 

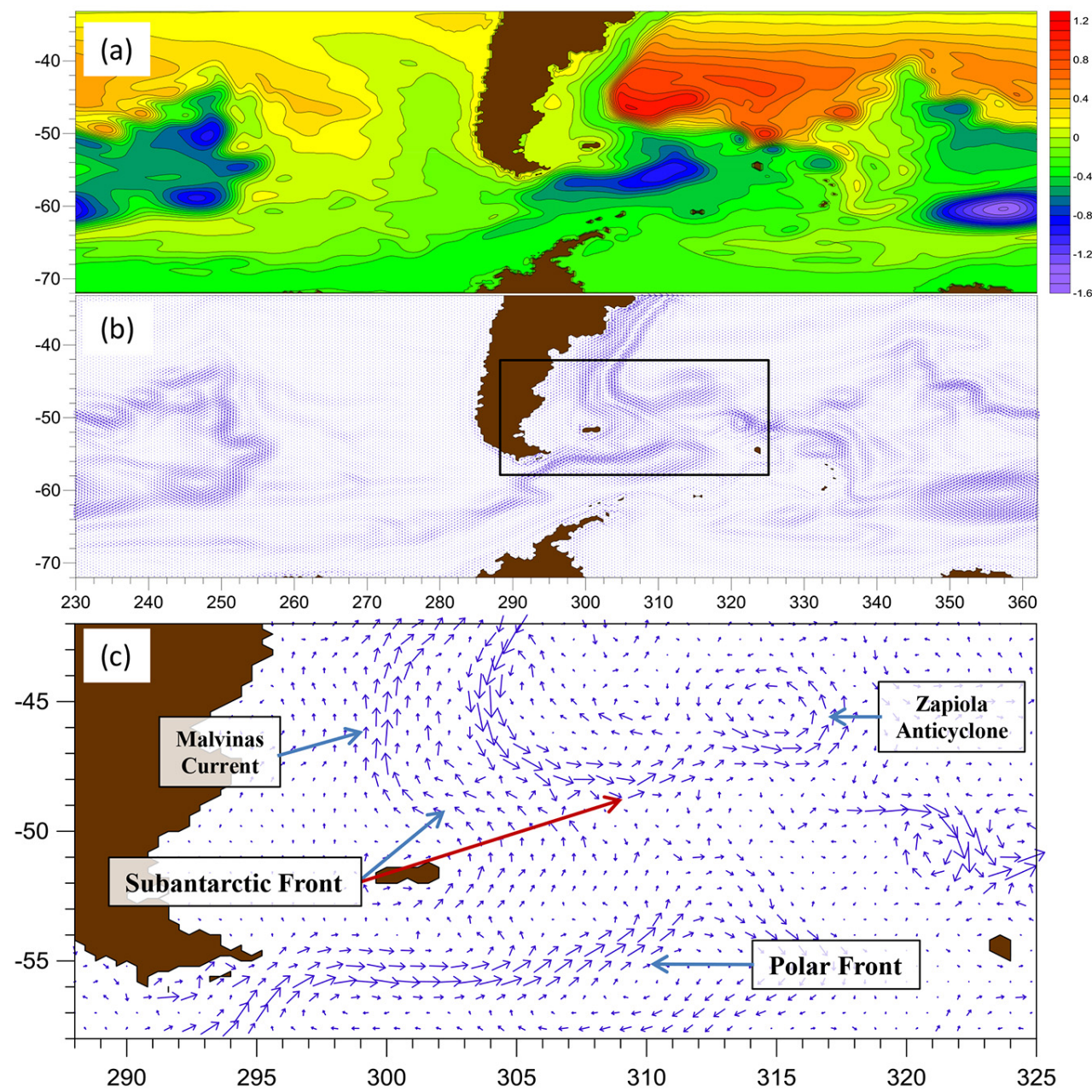

Fig. 5. (a) Mean SSH (in m). (b) Mean depth-integrated currents. (c) Zoom of the current field delimited by the rectangle in (b).

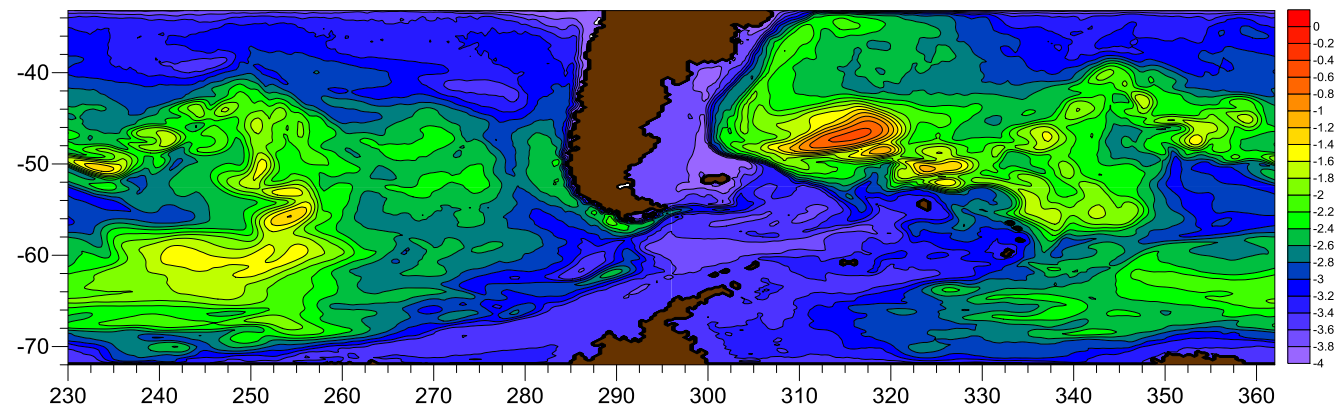

Fig. 6. Logarithm of the rms of the low-frequency SSH signal.

The analysis will therefore be focused on this region. Figure $7 \mathrm{~b}$ shows the time series of the SSH taken at point P1 where the variability is maximum (see Fig. 7a), which is $\sim 2^{\circ}$ south of the ZA center. The behavior yields a chaotic vacillation of $O(1 \mathrm{~m})$ that has a bimodal character: a detailed analysis will be carried out within the 10-year reference interval delimited by the red lines in Fig. $7 \mathrm{~b}$.
Figure 8 shows the SSH (total signal $\eta$ : black line; lowfrequency signal $\tilde{\eta}$ : blue line) at P1 during the reference interval; the SSH maps in the AB corresponding to the two sequences of six instants denoted by the green and red dots in Fig. 8 are shown in Fig. 9. In sequence (a) a well-defined ZA centered at $315^{\circ} \mathrm{E}, 46^{\circ} \mathrm{S}$ is present at $t=24600$ days, corresponding to a SSH maximum at P1, but 1 year before $(t=$ 

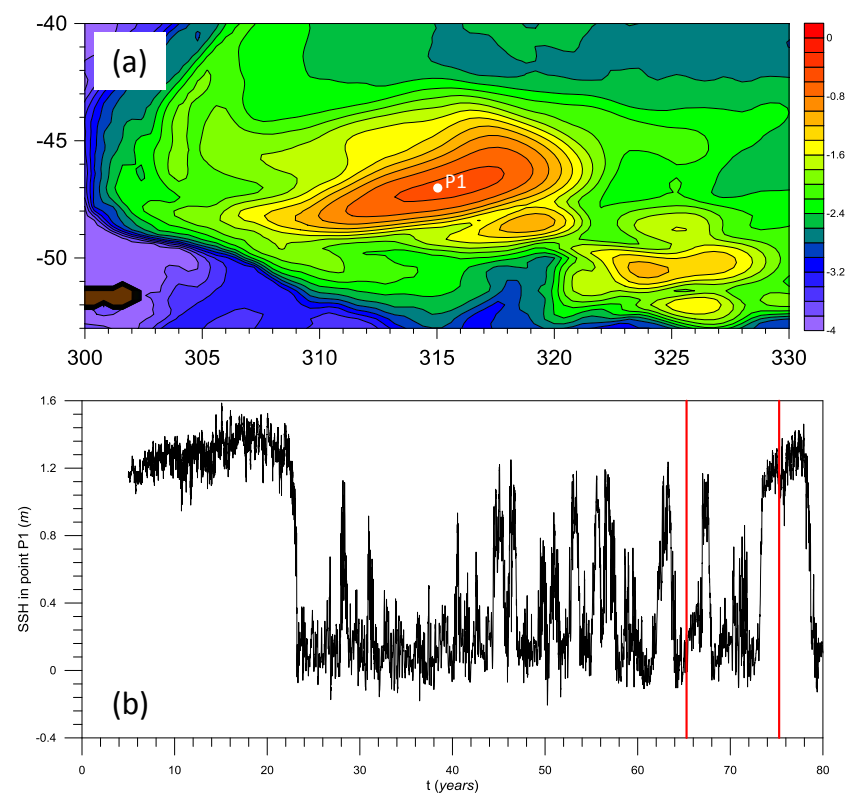

Fig. 7. (a) Logarithm of the rms of the low-frequency SSH signal in the Argentine Basin. (b) SSH at P1 (the analyses are carried out within the 10-year reference interval delimited by the red lines).

24200 days $)$ and after $(t=25000$ days $)$ the anticyclonic circulation is weaker and shifted westward by $2-5^{\circ}$, while a cyclonic circulation moving from the southeast intensifies and takes its place. Sequence (b) shows an abrupt transition from a collapsed but quite variable ZA $(t=26200-26600$ days $)$ to an intense ZA ( $t=27000-27200$ days). These transitions from a quasi-climatological state of the ZA (denoted as "active state" heretofore) to a collapsed ZA (and vice versa) are very similar to the variations of the ZA documented by Saraceno et al. (2009). The hypothesis is therefore that the oceanic intrinsic variability plays an important role in this phenomenon.

The preceding analysis has shown that a ZA in an active state is characterized by large values of $\tilde{\eta}$ at $\mathrm{P} 1(\tilde{\eta} \approx$ $1 \mathrm{~m}$ ) while, for a collapsed ZA, $\tilde{\eta} \approx 0-0.3 \mathrm{~m}$; to this respect, Fig. $7 \mathrm{~b}$ may provide qualitative information on the character and statistics of the transitions. However, $\tilde{\eta}$ gives only very local information and is not necessarily indicative of a circulation regime. A better way to characterize the ZA state is to rely on the (dimensionless) relative vorticity $\zeta$ (and of its low-frequency version $\tilde{\zeta}$ ) averaged over specific regions of the AB. The two maps in Fig. 10 show $\langle\tilde{\zeta}\rangle$ in a collapsed ( $t=25000$ days) and active state ( $t=27200$ days); it is evident that the two sectors A and B can very efficiently characterize the ZA state in terms of $\langle\tilde{\zeta}\rangle$ averaged in each of them.

The graph in Fig. 10 shows $\langle\zeta\rangle_{\mathrm{A}}$ (red line) and $\langle\zeta\rangle_{\mathrm{B}}$ (blue line) as a function of time for the reference interval: as could be expected, in a collapsed state $\langle\zeta\rangle_{\mathrm{A}}>0$ and $\langle\zeta\rangle_{\mathrm{B}}<0$ whereas for an active state both parameters are positive, with a tendency of $\langle\zeta\rangle_{B}$ to be greater. Figure 11 shows the scatter

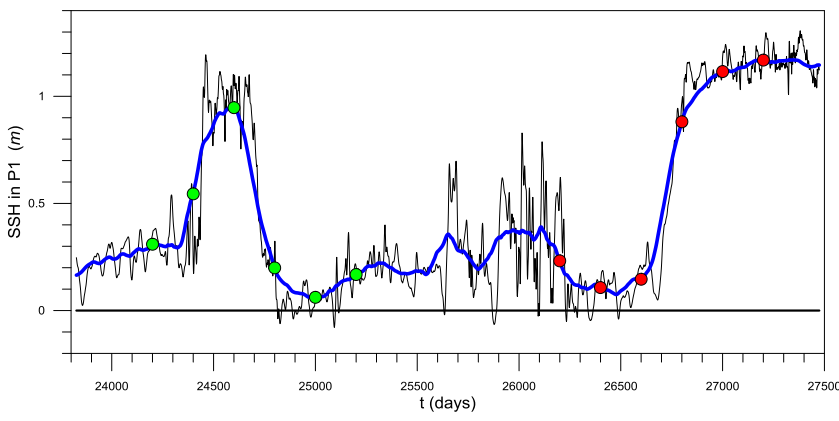

Fig. 8. SSH at P1 for the reference interval (black line: total signal; blue line: low-frequency signal). The SSH snapshots corresponding to the green/red dots are shown in Fig. 9.

plot of $\langle\zeta\rangle_{\mathrm{B}}$ versus $\langle\zeta\rangle_{\mathrm{A}}$ for the whole 80 year integration: the active state is represented by the compact cluster with $\langle\zeta\rangle_{\mathrm{B}}>0$ while the collapsed state with $\langle\zeta\rangle_{\mathrm{B}}<0$ is represented by a more diffuse cluster, which implies that this state cannot be characterized by a well-defined circulation pattern, as is the case for the active state. Moreover, the abrupt character of the transitions is clearly shown by the small number of dots in the intermediate range. Possible mechanisms that govern this LFV will be discussed in Sect. 5 .

\section{Intrinsic high-frequency variability}

In this section the high-frequency component of the intrinsic variability is analyzed, while its relation with the LFV will be considered in the next section. The high-frequency component is defined here in terms of the SSH as the residual $\eta^{\prime}=\eta-\tilde{\eta}$, and therefore includes periods shorter than $T=200$ days. Figure 12 shows the rms of $\eta^{\prime}$ in the AB: a region of intense variability crosses the isobaths from the deep sea just off the continental shelf in the southwestern side of the $\mathrm{ZR}$, reaching the peak of the ZR itself, and presents two maxima at $\mathrm{P} 2\left(313^{\circ} \mathrm{E}, 47^{\circ} \mathrm{S}\right)$ and $\mathrm{P} 3\left(317^{\circ} \mathrm{E}, 45.5^{\circ} \mathrm{S}\right)$.

Figure 13a shows the time series of $\eta^{\prime}$ (red line) and $\tilde{\eta}$ (blue line) at P3. The HFV has a very intermittent behavior and yields an apparent relation with the LFV, in that the high frequency is more energetic in the collapsed state, corresponding to low values of $\tilde{\eta}$. Because of the intermittency of the HFV (also found in altimeter data by Tai and Fu, 2005; $\mathrm{Fu}, 2007)$, a spectral analysis can most appropriately be carried out by means of the continuous wavelet transform (e.g., Torrence and Compo, 1998). Figure 13b shows the amplitude $w(s, t)$ of the corresponding wavelet transform of $\eta$, where $s$ is the timescale (only the scales $s \leq 200$ days are shown). The period band of 0-50 days includes topographic Rossby waves and modes (Fu et al., 2001): here the amplitude is reduced and very intermittent over timescales ranging from 100 to 300 days (in agreement with Fu, 2007). In the period band of 100-150 days the amplitude is higher and less intermittent, but is often clearly related to the higher frequency 
(a)
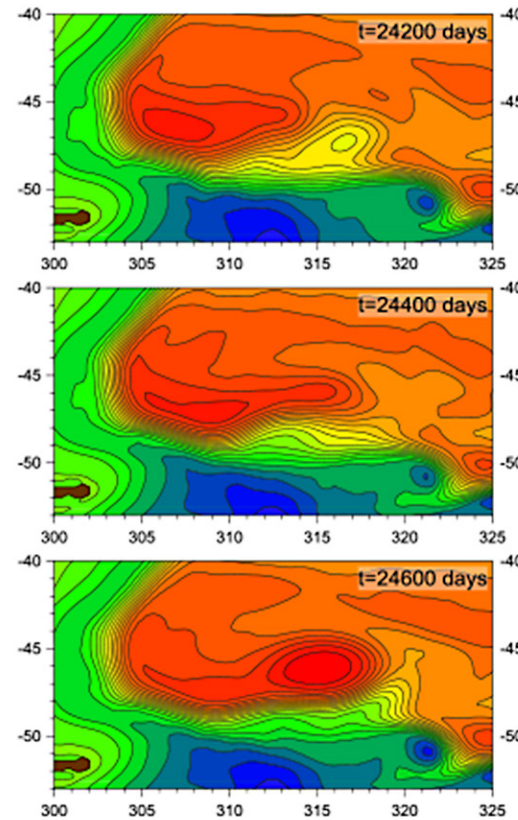

300
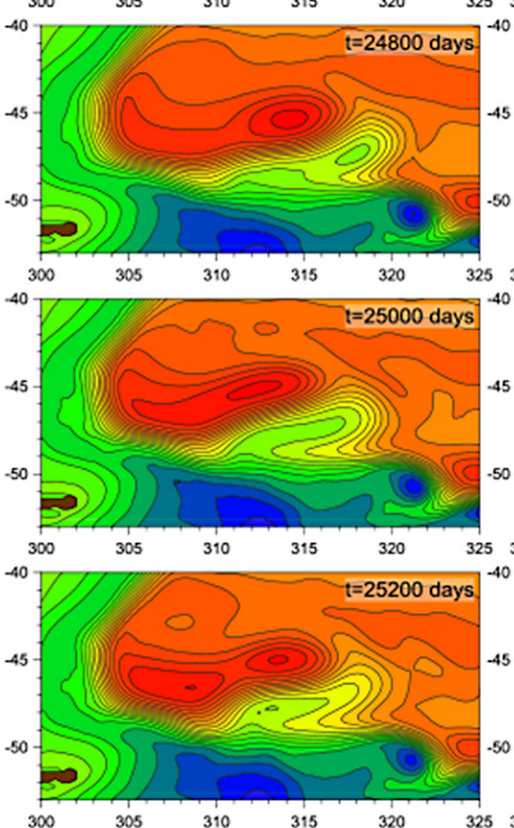

(b)
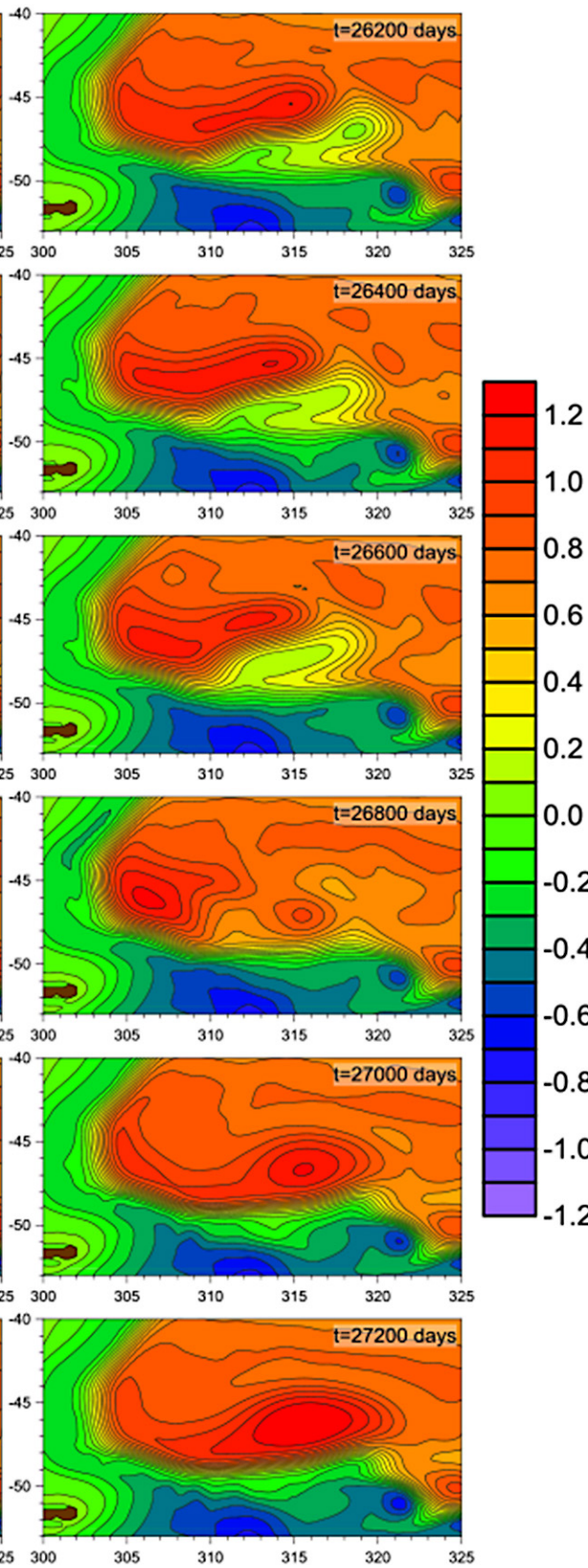

Fig. 9. Snapshots of the low-frequency SSH signal (in m) corresponding to the green (a) and red (b) dots in Fig. 8.

variability (this is also consistent with the results of $\mathrm{Fu}, 2007$, but see the next section for a more careful comparison).

For a qualitative analysis of the flow patterns of the HFV, a sequence of snapshots of the SSH residual $\eta^{\prime}$ is reported in Fig. 14. The 25-day-long sequence is sampled every 5 days and corresponds to a maximum in the wavelet amplitude at $\mathrm{P} 3$ in the period band 0-50 days (see the oval in Fig. 13b). Very complex patterns arise, with length scales ranging from $O\left(1^{\circ}\right)$ or less for the mesoscale up to $O\left(5-10^{\circ}\right)$ for topographic Rossby waves. The variability is mainly confined over the ZR and shows a clear propagation of features originating from the southwestern side of the ZR itself. A wave train follows the southern limits of the rise and turns counterclockwise along its eastern flank: in doing so the vortices undergo substantial stretching and deformation. These waves can be interpreted as topographic Rossby modes (Fu et al., 2001; Tai and Fu, 2005; Weijer et al., 2007a, b). The patterns appear more complex than those typically shown in 

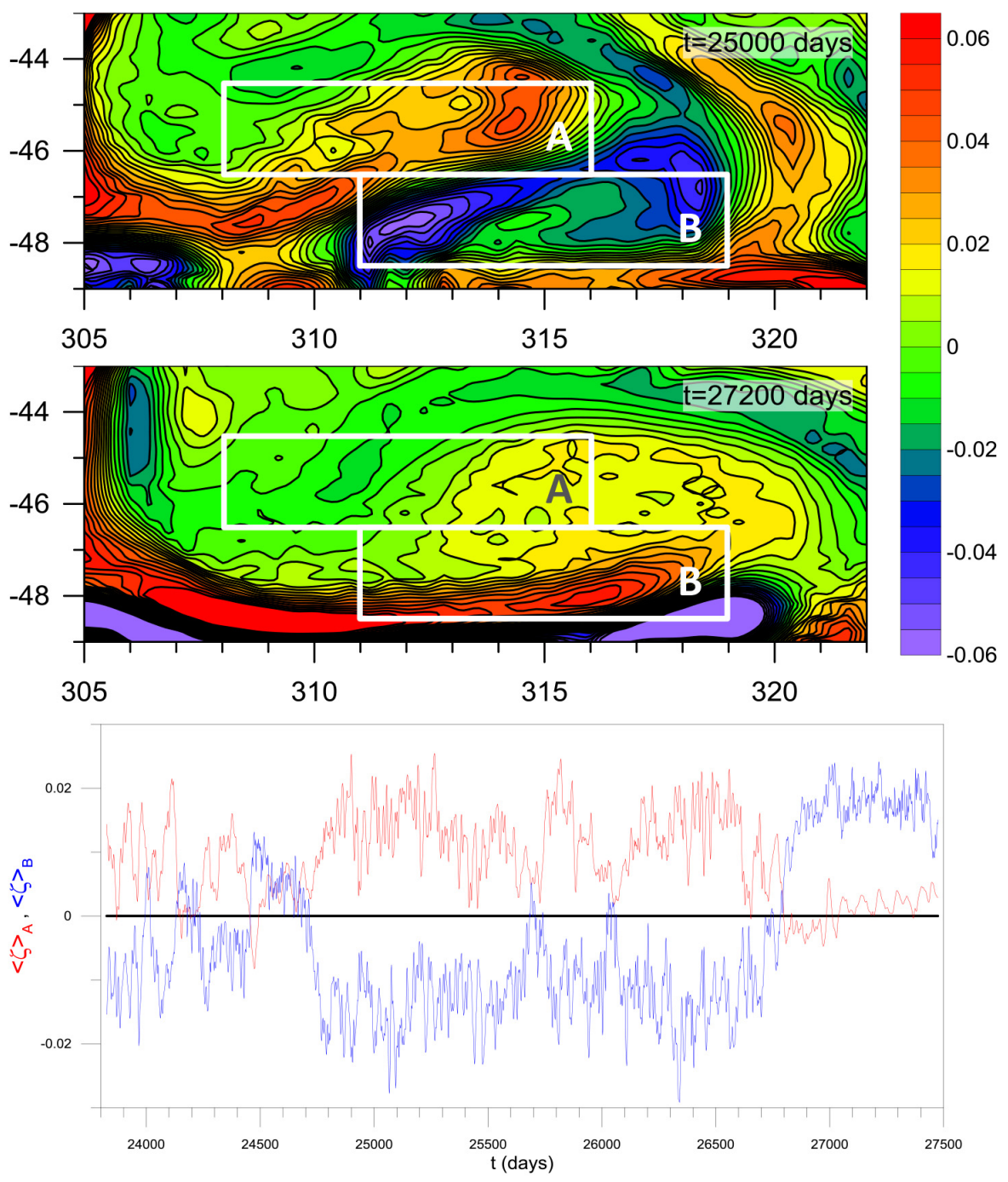

Fig. 10. Upper panels: low-frequency relative vorticity $\langle\tilde{\zeta}\rangle$ at $t=25000$ and $t=27200$ days. Lower panel: time series of $\langle\zeta\rangle$ averaged in sectors A and B for the 10-year reference interval.

this location by altimeter data after high-pass filtering the motions with timescales longer than $\sim 1$ month (e.g., Fu et al., 2001). This is because our high-frequency signal contains also the longer-term variability associated with the mesoscale eddy field.

A general feature that deserves to be emphasized is the varying length scale of the vortices, which is smaller in the southwestern side of the ZR and tends to increase as the pattern propagates. This transition from the mesoscale to the Rossby mode scale is compatible with the energy exchange found to be at work in this region by Fu (2007); this aspect will be analyzed in more detail in the next section. From this qualitative analysis it appears that the topographic Rossby modes in the ZR are not necessarily generated directly by the wind forcing, but may also be of intrinsic origin. Presumably this happens through low-frequency fluctuations of the local circulation (e.g., see Pierini, 1996), that in this case are intrinsic. This also supports the hypothesis that the wind-generated topographic Rossby modes may as well be generated through the same mechanism, in which case the current fluctuations that produce them are not intrinsic but directly wind-driven (e.g., Pierini et al., 2002; see Sect. 5.3 for further discussion).

\section{Relation between low- and high-frequency variability}

In the Sects. 3 and 4 we have identified intrinsic LFV on interannual timescales yielding regime switches from an active ZA to a collapsed ZA, but HFV was found as well. A high-frequency range (HFR, 0-50 days) includes topographic Rossby modes; the behavior in an intermediate highfrequency range (IHFR, 100-150 days) appears to be related to that of the HFR. Now, a question arises: is there a 


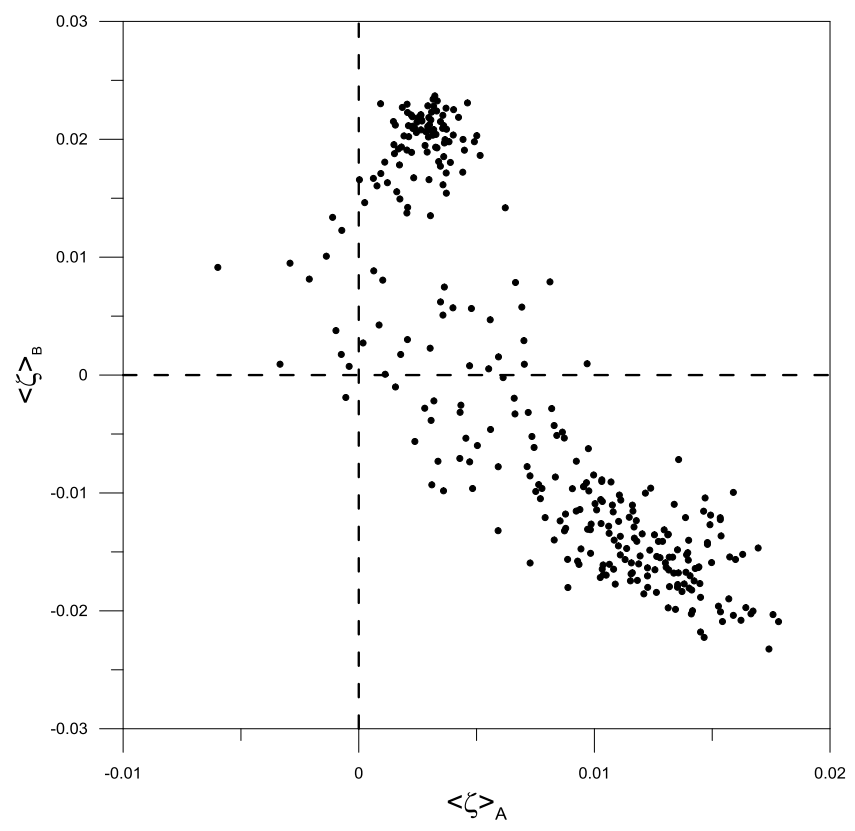

Fig. 11. Scatter plot of $\langle\tilde{\zeta}\rangle$ averaged in sectors A and B.

relation between these three forms of intrinsic variability in our model results? In general, analyzing this issue is fundamental from a theoretical viewpoint, as it could shed light into dynamical mechanisms that involve a wide range of spatial and temporal scales.

A preliminary qualitative analysis of this kind is presented here. First of all we define a Zapiola index as follows:

$Z=\langle\tilde{\zeta}\rangle_{\mathrm{A}}-\langle\tilde{\zeta}\rangle_{\mathrm{B}}$

The graph in Fig. 10 shows $\langle\zeta\rangle_{\mathrm{A}}$ and $\langle\zeta\rangle_{\mathrm{B}}$ for the reference interval: the two signals are virtually in counterphase in a ZA collapsed state while they tend to be both positive in an active ZA state, with the second signal being higher. Thus, $Z$ as defined in Eq. (1) (and shown by the green line in Fig. 15 for the reference interval) is a good global, low-frequency indicator of the ZA state, for which a large positive value implies a collapsed state, while a negative or small positive value implies an active state. To construct high-frequency indices we can define the integral of the wavelet amplitude at the reference point $\mathrm{P} 3$ within two timescales:

$W_{s_{1}, s_{2}}(t)=\int_{s_{1}}^{s_{2}} w_{\mathrm{P}_{3}}(s, t) \mathrm{d} s$.

Thus, the two indices $W_{1,50}(s=1$ day is the smallest scale of the wavelet transform) and $W_{100,150}$ (red and blue lines in Fig. 15, respectively) are good indicators of the behavior in the HFR and IHFR, respectively. We pass to discuss three possible interactions suggested by Fig. 15 and by other experimental and numerical investigations.

\subsection{Relation between $W_{100,150}$ and $Z$}

Several works (e.g., Dewar, 1998; Bigorre, 2005; Bigorre and Dewar, 2009; Volkov and Fu, 2008; Venaille et al., 2011, Saraceno and Provost, 2012) have suggested that the mesoscale eddy activity provides the main source of energy of the ZA. By studying the correlation between the eddy kinetic energy and the LFV of the ZA with 15 years of altimeter records, Saraceno et al. (2009) found support for that hypothesis, suggesting a rapid adjustment of the ZA to changes in the eddy kinetic energy. By using high-resolution altimeter data produced by the Archiving, Validation and Interpretation of Satellite Oceanographic data (AVISO) project, $\mathrm{Fu}$ (2007) found that the variance-preserving spectrum of the mesoscale energy time series in the $A B$ is spread over a wide range of frequencies, with the majority in the seasonal-tointerannual range, but a significant variance is present also in the range of 100-160 days (basically our IHFR); thus, $W_{100,150}$ represents a good index for the high frequency mesoscale in the $\mathrm{AB}$.

In our model results, both transitions present in the reference interval from a collapsed to an active ZA (occurring at $t \approx 24400$ and $t \approx 26700$ days, when $Z$ decreases abruptly, Fig. 15) are preceded by a large $W_{100,150}$, which decreases as the transition to the active state is occurring, with a lag of 100-300 days between the two signals. Moreover, the collapse of the ZA at $t \approx 24700$ days is followed by an increase of $W_{100,150}$ with a lag of $\sim 200$ days. This behavior is compatible with a transfer of energy from the eddy field to the large-scale circulation during the collapsed ZA-active ZA transition, and vice versa, and therefore appears to be in basic agreement with the theoretical and experimental arguments reported above: it is interesting to note that purely intrinsic oceanic mechanisms are able to produce such a dynamical process.

\subsection{Relation between $W_{1,50}$ and $W_{100,150}$}

Using altimeter observations, Fu (2007) analyzed the possible relationship between the 25-day barotropic Rossby waves and the energetic baroclinic mesoscale eddies in the ZA region. The wave amplitude was found to be coherent with the energy of the high-frequency mesoscale variability, in that when the latter decreases the wave amplitude increases and vice versa, suggesting an exchange of energy between the two scales. An indication of this behavior in our model results (for which changes in the wave amplitude and in the mesoscale eddy field are represented by $W_{1,50}$ and $W_{100,150}$, respectively) can be found in the intervals $t \approx 23800-24700$ days and $t \approx 25900-26400$ days (Fig. 15), which both precede the transition from a collapsed to an active ZA state. The latter property is particularly interesting, as it suggests a relationship between the energy exchange in the high-frequency ranges and the large-scale LFV of the ZA that deserves to be analyzed in future studies. 


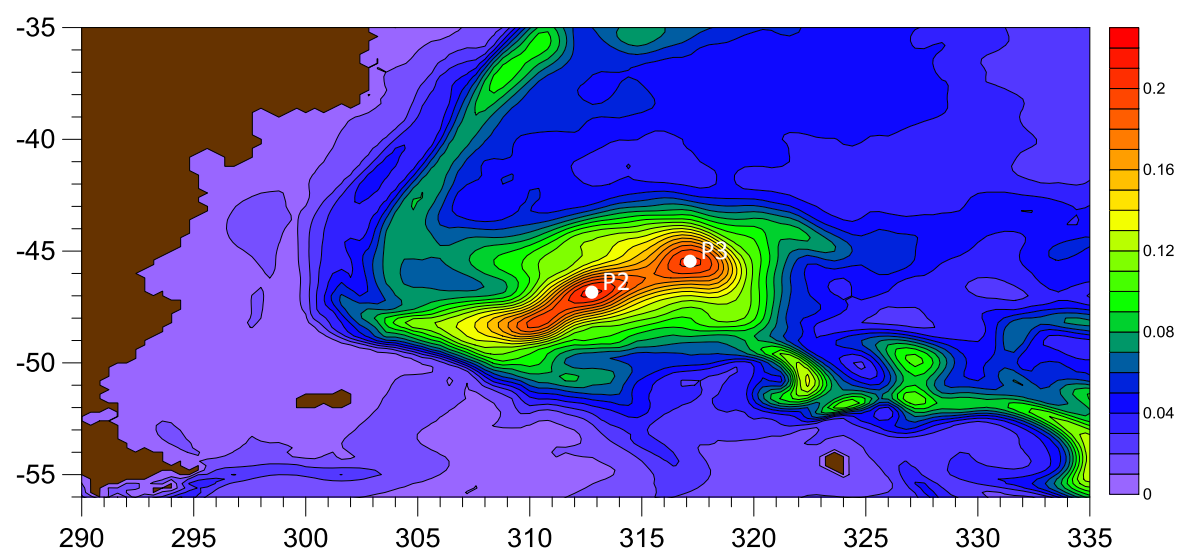

Fig. 12. Rms of the high-frequency SSH signal (in $\mathrm{m}$ ) in the Argentine Basin.
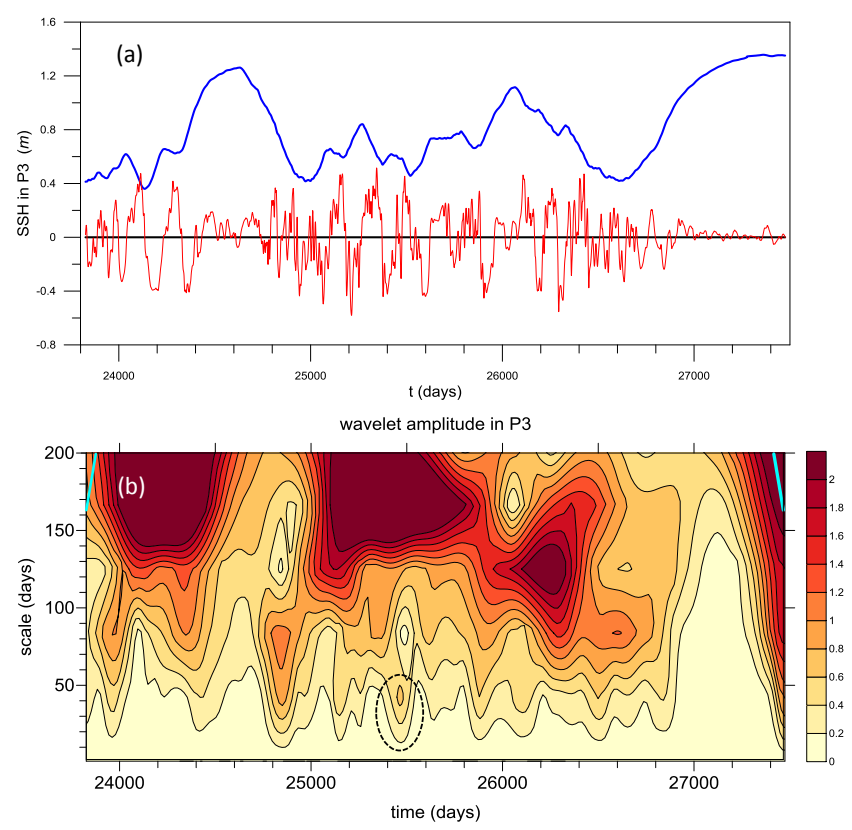

Fig. 13. (a) Low-frequency SSH at P3 (blue line) and corresponding high-frequency residual (red line) for the reference interval. (b) Wavelet amplitude of the SSH signal for the same point and time interval (the cyan lines indicate the cone of influence).

\subsection{Relation between $W_{1,50}$ and $Z$}

During the transition from an active to a collapsed $\mathrm{ZA}$ in the interval $t \approx 24600-25000$ days no relationship such as the one described above seems to exist between $W_{1,50}$ and $W_{100,150}$; however, the sudden increase of the energy level in $W_{1,50}$ follows the abrupt collapse of the ZA. This suggests that an impulsive generation of topographic Rossby modes can be active, perhaps with the involvement of mesoscale eddies as discussed at the end of Sect. 4. To this respect, laboratory experiments in a rotating tank performed by Pierini et al. (2002) confirmed the hypothesis put forward in a previous numerical study on topographic Rossby modes in the Strait of Sicily (Pierini, 1996), according to which topographic Rossby modes can effectively be excited by rapid changes of the mean flow (provided in the tank by the movement of a large paddle). In a Rossby mode the timescale is set by the bottom topography and coastlines (if present) and not by the spectral content of the wind field, which only indirectly forces the modes through changes in the mean flow. This may explain why Fu et al. (2001) did not find any significant wind variability at periods close to 25 days in the $\mathrm{AB}$, nor could they find any significant correlation between the variability of the wave amplitude with the variability of the wind-stress curl. Thus, the impulsive generation of topographic Rossby modes, which appears to be active in our numerical results, should be considered when explaining the variability in our HFR.

It is clear that understanding the intricate mutual interaction among these three different temporal scales requires a much deeper investigation than that presented in this analysis, which cannot by itself determine any causality between the various scales. Nonetheless, these results can complement those quoted above for future, more advanced investigations in this very peculiar and interesting oceanic site.

\section{Conclusions}

In this paper, an eddy-permitting sigma-coordinate ocean model has been applied to a large portion of the Southern Ocean with the aim of identifying and analyzing low- and high-frequency fluctuations of intrinsic oceanic origin - a fundamental task for understanding the role of the ocean in the global climate. The approach is typical of processoriented studies of the intrinsic oceanic variability (idealized but relatively realistic steady winds and stratification) but a realistic topography is used because barotropic motions, and so topographic interactions, are important here. The obtained mean flow is in good agreement with observations 

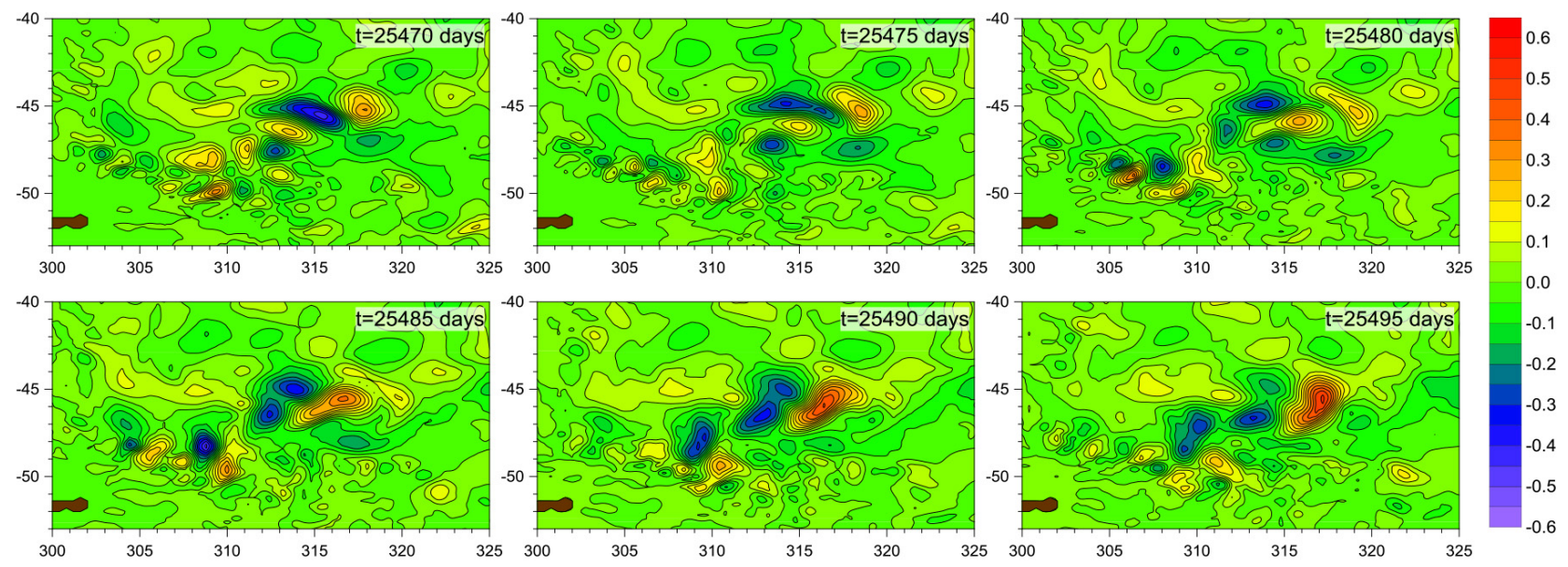

Fig. 14. Snapshot sequence of the SSH high-frequency residual (in $\mathrm{m}$ ) corresponding to a high-frequency maximum of the wavelet amplitude at P3 (see the oval in Fig. 13b).

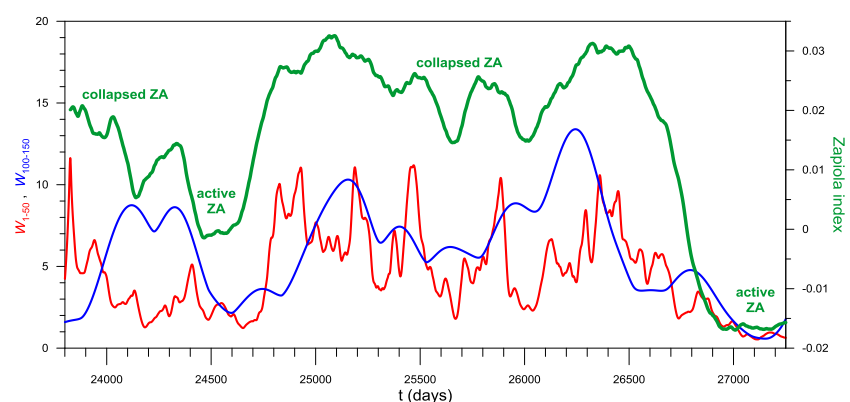

Fig. 15. Green line: Zapiola index. Red and blue lines: integrated wavelet amplitudes $W_{1,50}$ and $W_{100,150}$, respectively.

as far as the transport through the Drake Passage and the structure of the main Antarctic Circumpolar Current fronts are concerned. Important variability of both low- and highfrequency nature is found, being particularly intense in the branch of the Subantarctic Front corresponding to the Argentine Basin, which, due to its crucial location plays an active role in determining the circulation in the southwestern Atlantic sector of the Southern Ocean. The variability over interannual timescales shows a bimodal behavior of the Zapiola Anticyclone, connecting an active state to a state in which the anticyclonic circulation collapses and sometimes reverses locally: this is in substantial agreement with the altimeter observations of Saraceno et al. (2009). The highfrequency residual signal shows clear evidence of mesoscale propagating patterns particularly along the southern flanks of the Zapiola Rise, and a counterclockwise rotation of largerscale topographic Rossby modes over the rise, in substantial agreement with observations. Thus, the main conclusion is that these forms of variability are compatible with intrinsic generation mechanisms all internal to the ocean system. A preliminary analysis of the mutual relationship between the low-frequency variability and two components of the high-frequency variability puts in evidence interesting agreements with observations and previous theoretical and modeling studies, and at the same time suggests a deeper analysis of the results.

Future perspectives include new simulations using a domain with a larger latitudinal extension, so as to represent the Brazil Current and the Malvinas-Brazil Current Confluence. This will allow us to directly compare the modeled eddy field in the southwestern Atlantic with that observed from altimeter data (e.g., Saraceno and Provost, 2012) and to assess its contribution to the low-frequency variability of the Zapiola Anticyclone. Other studies will be devoted to analyzing the sensitivity of the model response to changes in the forcing and parameterizations. For example, changing the amplitude of the wind forcing and/or the parameterization of dissipative effects can produce important modifications in the intrinsic variability (e.g., see the analysis of Pierini et al., 2009, in the context of the Kuroshio Extension bimodality). Another fundamental aspect that should be analyzed is the effect of time-dependent forcing on the emergence of the intrinsic oceanic variability. The intrinsic variability is often in the form of relaxation oscillations that are self-sustained beyond a given tipping point (global bifurcation in some state space) associated with a particular control parameter, while they do not emerge below that threshold under steady forcing (e.g., Simonnet et al., 2005). However, the same intrinsic relaxation oscillations can emerge even below the bifurcation point provided an appropriate noise (e.g., Sura et al., 2001; Frankcombe et al., 2009; Pierini, 2010, 2012), a deterministic time-dependent component (e.g., Otterå et al., 2010; Crucifix, 2012; Pierini, 2014) or both (e.g., Pierini, 2011) are added to the forcing. Thus, using steady forcing, as done here, constitutes only the first step toward the identification of the intrinsic variability; further studies that include both 
wind noise and the main modes of atmospheric variability in the Southern Ocean will have to be carried out.

Acknowledgements. This research was supported by the MATHACC Project funded by the Italian "Programma Nazionale di Ricerche in Antartide" (PNRA contract no. 2010/A2.11-2753). The work of H. A. Dijkstra was also sponsored by the COMPLEXITY Project PreKurs funded by the Netherlands Organization for Scientific Research (NWO). We would like to thank two anonymous reviewers, whose detailed comments helped improve the manuscript.

Edited by: M. Hecht

\section{References}

Barnier, B., Marchesiello, P., de Miranda, A. P., Molines, J.-M., and Coulibaly, M.: A sigma-coordinate primitive equation model for studying the circulation in the South Atlantic. part I: Model configuration with error estimates, Deep-Sea Res., 45, 543-572, 1998.

Barnier, B., Madec, G., Penduff, T., Molines, J.-M., Treguier, A.M., Le Sommer, J., Beckmann, A., Biastoch, A., Böning, C., Dengg, J., Derval, C., Durand, E., Gulev, S., Remy, E., Talandier, C., Theetten, S., Maltrud, M., McClean, J., and De Cuevas, B.: Impact of partial steps and momentum advection schemes in a global ocean circulation model at eddy permitting resolution, Ocean Dynam., 56, 543-567, 2006.

Beckmann, A. and Haidvogel, D.: Numerical simulation of flow around a tall isolated seamount. part I: Problem formulation and model accuracy, J. Phys. Oceanogr., 23, 1736-1753, 1993.

Bigorre, S.: Topographic effects on wind driven oceanic circulation, Ph.D. Thesis, Florida State University, 100 pp., 2005

Bigorre, S. and Dewar, W. K.: Oceanic time variability near a large scale topographic circulation, Ocean Model., 29, 176-188, 2009.

Crucifix, M.: Oscillators and relaxation phenomena in Pleistocene climate theory, Philos. Trans. Roy. Soc. London, A370, 1140$1165,2012$.

De Miranda, A. P., Barnier, B., and Dewar, W. K.: On the dynamics of the Zapiola Anticyclone, J. Geophys. Res., 104, 21139-21149, 1999.

Dewar, W. K.: Topography and barotropic transport control by bottom friction, J. Mar. Res., 56, 295-328, 1998.

Dijkstra, H. A.: Nonlinear Physical Oceanography, Springer, 532 pp., 2005.

Dijkstra, H. A. and de Ruijter, W. P. M.: On the physics of the Agulhas Current: steady retroflection regimes, J. Phys. Oceanogr., 31, 2971-2985, 2001.

Dijkstra, H. A. and Ghil, M.: Low-frequency variability of the largescale ocean circulation: A dinamical systems approach, Rev. Geophys., 43, RG3002, doi:10.1029/2006JC003679, 2005.

Frankcombe, L. M., Dijkstra, H. A., and Von der Heydt, A. S.: Noise induced multidecadal variability in the North Atlantic: excitation of normal modes, J. Phys. Oceanogr., 39, 220-233, 2009.

$\mathrm{Fu}$, L.-L.: Interaction of mesoscale variability with large-scale waves in the Argentine Basin, J. Phys. Oceanogr., 37, 787-793, 2007.
Fu, L.-L., Cheng, B., and Qiu, B.: 25-day period large-scale oscillations in the Argentine Basin revealed by the TOPEX/Poseidon altimeter, J. Phys. Oceanogr., 31, 506-517, 2001.

Garzoli, S. L., Piola, A. R., Speich, S., Baringer, M., Goni, G., Donohue, K., Meinen, C., and Matano, R. P.: A monitoring system for heat and mass transports in the South Atlantic as a component of the meridional overturning circulation, Workshop Report: Estancia San Ceferino, Buenos Aires, Argentina, 8-10 May 2007, 38 pp., International CLIVAR Project Office, Southampton, UK, 2008.

Giarolla, E. and Matano, R. P.: The low-frequency variability of the Southern Ocean circulation, J. Climate, 26, 6081-6091, 2013.

Haney, R. L.: On the pressure gradient force over steep topography in sigma coordinate ocean models, J. Phys. Oceanogr., 21, 610 619, 1991.

Hogg, A. M. and Blundell, J. R.: Interdecadal variability of the Southern Ocean, J. Phys. Oceanogr., 36, 1626-1645, 2006.

Hughes, C. W., Stepanov, V. N., Fu, L.-L., Barnier, B., and Hargreaves, G. W.: Three forms of variability in Argentine Basin ocean bottom pressure, J. Geophys. Res., 112, C01011, doi:10.1103/PhysRevE.85.027101, 2007.

Le Bars, D., de Ruijter, W. P. M., and Dijkstra, H. A.: A new regime of the Agulhas Current retroflection: turbulent choking of IndianAtlantic leakage, J. Phys. Oceanogr., 42, 1158-1172, 2012.

Marchesiello, P., Barnier, B., and de Miranda, A. P.: A sigmacoordinate primitive equation model for studying the circulation in the South Atlantic. part II: Meridional transport and seasonal variability, Deep-Sea Res., 45, 573-608, 1998.

Mellor, G. L.: Users guide for a three-dimensional, primitive equation, numerical ocean model, Prog. in Atmos. and Ocean Sci., Princeton University, 53 pp., 2003.

Mellor, G. L. and Yamada, T.: Development of a turbulence closure model for geophysical fluid problems, Rev. Geophys. Space Phys., 20, 851-875, 1982.

O'Kane, T. J., Matear, R. J., Chamberlain, M. A., Risbey, J. S., Sloyan, B. M., and Horenko, I.: Decadal variability in an OGCM Southern Ocean: intrinsic modes, forced modes and metastable states, Ocean Model., 69, 1-21, 2013.

Otterå, O. H., Bentsen, M., Drange, H., and Suo, L.: External forcing as a metronome for Atlantic multidecadal variability, Nat. Geosci., 3, 688-694, 2010.

Penduff, T., Juza, M., Barnier, B., Zica, J., Dewar, W. K., Treguier, A.-M., Molines, J.-M., and Audiffren, N.: Sea level expression of intrinsic and forced ocean variabilities at interannual time scales, J. Climate, 24, 5652-5670, 2011.

Pierini, S.: Topographic Rossby modes in the Strait of Sicily, J. Geophys. Res., 101, 6429-6440, 1996.

Pierini, S.: A Kuroshio Extension system model study: decadal chaotic self-sustained oscillations, J. Phys. Oceanogr., 36, 16051625, 2006.

Pierini, S.: On the crucial role of basin geometry in double-gyre models of the Kuroshio Extension, J. Phys. Oceanogr., 38, 1327 1333, 2008.

Pierini, S.: Coherence resonance in a double-gyre model of the Kuroshio Extension, J. Phys. Oceanogr., 40, 238-248, 2010.

Pierini, S.: Low-frequency variability, coherence resonance and phase selection in a low-order model of the wind-driven ocean circulation, J. Phys. Oceanogr., 41, 1585-1604, 2011. 
Pierini, S.: Stochastic tipping points in climate dynamics, Phys. Rev. E, 85, 027101, doi:10.1029/2011GL048401, 2012.

Pierini, S.: Kuroshio Extension bimodality and the North Pacific Oscillation: a case of intrinsic variability paced by external forcing, J. Climate, 27, 448-454, 2014.

Pierini, S. and Dijkstra, H. A.: Low-frequency variability of the Kuroshio Extension, Nonlin. Processes Geophys., 16, 665-675, doi:10.5194/npg-16-665-2009, 2009.

Pierini, S., Fincham, A., Renouard, D., D'Ambrosio, R., and Didelle, H.: Laboratory modeling of topographic Rossby normal modes, Dyn. Atmos. Oceans, 35, 205-225, 2002.

Pierini, S., Dijkstra, H. A., and Riccio, A.: A nonlinear theory of the Kuroshio Extension bimodality, J. Phys. Oceanogr., 39, 22122229, 2009.

Piola, A. R. and Gordon, A. L.: Intermediate waters in the southwest South Atlantic, Deep-Sea Res., 36, 1-16, 1989.

Qiu, B. and Miao, W.: Kuroshio path variations south of Japan: bimodality as a self-sustained internal oscillation, J. Phys. Oceanogr., 30, 2124-2137, 2000.

Quattrocchi, G., Pierini, S., and Dijkstra, H. A.: Intrinsic lowfrequency variability of the Gulf Stream, Nonlin. Processes Geophys., 19, 155-164, doi:10.5194/npg-19-155-2012, 2012.

Rintoul, S. R., Hughes, C., and Olbers, D.: The Antarctic Circumpolar Current System, in: Ocean Circulation and Climate, Academic Press, 271-302, 2001.

Saraceno, M. and Provost, C.: On eddy polarity distribution in the southwestern Atlantic, Deep-Sea Res. I, 69, 62-69, 2012.

Saraceno, M., Provost, C., Piola, A. R., Bava, J., and Gagliardini, A.: Brazil Malvinas frontal system as seen from 9 years of advanced very high resolution radiometer, J. Geophys. Res., 109, C05027, doi:10.1029/2003JC002127, 2004.

Saraceno, M., Provost, C., and Zajaczkovski, U.: Long-term variation in the anticyclonic ocean circulation over the Zapiola Rise as observed by satellite altimetry: Evidence of possible collapses, Deep-Sea Res., 56, 1077-1092, 2009.

Saunders, P. and King, B. A.: Bottom currents derived from a shipborne ADCP on WOCE cruise A11 in the South Atlantic, J. Phys. Oceanogr., 25, 329-347, 1995.

Schmeits, M. J. and Dijkstra, H. A.: Bimodal behavior of the Kuroshio and the Gulf Stream, J. Phys. Oceanogr., 31, 34353456, 2001.
Sgubin, G.: A model study of the Southern Ocean dynamics: mean flow, intrinsic variability and teleconnections, Ph.D. Thesis, University of Naples "Federico II" and University of Naples "Parthenope", 130 pp., 2012.

Simonnet, E., Ghil, M., and Dijkstra, H. A.: Quasi-homoclinic behavior of the barotropic quasi-geostrophic double-gyre circulation, J. Mar. Res., 63, 931-956, 2005.

Smythe-Wright, D., and Boswell, S.: Abyssal circulation in the Argentine Basin, J. Geophys. Res., 103, 15845-15851, 1998.

Sura, P., Fraedrich, K., and Lunkeit, F.: Regime transitions in a stochastically forced double-gyre model, J. Phys. Oceanogr., 31, 411-426, 2001.

Tai, C.-K. and Fu, L.-L.: 25-day period large-scale oscillations in the Argentine Basin revisited, J. Phys. Oceanogr., 35, 14731479, 2005.

Torrence, C. and Compo, G. P.: A practical guide to wavelet analysis, Bull. Amer. Meteor. Soc., 79, 61-78, 1998

Trenberth, K. E., Olson, J. G., and Large, W. G.: A global ocean wind stress climatology based on ECMWF analyses, NCAR Technical Note NCAR/TN-338, 1989.

Venaille, A., Le Sommer, J., Molines, J.-M., and Barnier, B.: Stochastic variability of oceanic flows above topography anomalies, Geophys. Res. Lett., 38, L16611, doi:10.1029/2008JC004841, 2011.

Volkov, D. L., and Fu, L.-L.: The role of vorticity fluxes in the dynamics of the Zapiola Anticyclone, J. Geophys. Res., 113, C11015, doi:10.1029/2008JC004841, 2008.

Weatherly, G. L.: On deep-current and hydrographic observations from a mudwave region and elsewhere in the Argentine Basin, Deep-Sea Res., 40, 939-961, 1993.

Weijer, W., Vivier, F., Gille, S. T., and Dijkstra, H. A.: Multiple oscillatory modes of the Argentine Basin. Part I: statistical analysis, J. Phys. Oceanogr., 37, 2855-2868, 2007a.

Weijer, W., Vivier, F., Gille, S. T., and Dijkstra, H. A.: Multiple oscillatory modes of the Argentine Basin. Part II: the spectral origin of basin modes. J. Phys. Oceanogr., 37, 2869-2881, $2007 \mathrm{~b}$.

Whitworth, T., Nowlin,W. D., Pillsbury, R. D., Moore, M. I., and Weiss, R. F.: Observations of the Antarctic Circumpolar Current and deep boundary current in the southwest Atlantic, J. Geophys. Res., 96, 15105-15118, 1991. 